\title{
CORYNEBACTERIUM ACNES AND OTHER ANAEROBIC DIPHTHEROIDS FROM HUMAN SKIN
}

\author{
R. R. Marples* and K. J. McGinley \\ Duhring Laboratories, Hospital of the University of Pennsylvania, \\ 36th and Spruce Street, Philadelphia, Penna 19104, USA
}

\section{Plate XIII}

THE anaerobic diphtheroids are the commonest micro-organisms resident on the skin of the head and upper trunk (Evans, Smith, Johnston and Giblett, 1950; Marples, 1965); similar organisms live in the nose and gut (Rosebury, 1962). On the scalp they are responsible for the production of free fatty acids from sebaceous triglycerides (Marples, Downing and Kligman, 1971 and 1972); these acids are thought to be important in the defence of the skin against colonisation by foreign organisms, especially streptococci (Burtenshaw, 1945; Lacey, 1968 and 1969), and may also be significant in the pathogenesis of acne vulgaris (Strauss and Kligman, 1960). The anaerobic diphtheroids are also occasionally isolated from blood cultures and other clinical specimens, and there is considerable interest in whether they can be pathogenic in systemic infections (Smith and Bodily, 1968; Rasmussen, Gibbons and Socransky, 1966). When cultures are contaminated with anaerobic diphtheroids from the skin, these may outgrow other anaerobic organisms (Johnson and Cummins, 1972). There is thus a need for convenient means of their classification and identification.

Strains of anaerobic diphtheroids from the skin have shown biochemical differences that might have led to the definition of two or more species (Südmerson and Thompson, 1910; Brzin, 1964), and Voss (1970) formally divided human strains into two groups, I and II, on the basis of biochemical and serological tests. Other workers have treated human strains as one species, Corynebacterium or Propionibacterium acnes (Puhvel, 1968; Ray and Kellum, 1970). Several species described by the French worker (Prévot, 1966) were all considered by Zierdt, Webster and Rude (1968) to belong to the species $C$. acnes. Recently, Johnson and Cummins (1972) reported the results of an investigation of DNA homology and cell-wall composition in 80 anaerobic coryneform bacilli and described four types of which two were thought to represent varieties of $C$. acnes differing in cell-wall composition, whilst the others represented C. avidum and C. granulosum. All five of the strains from Voss' group II that were tested were $C$. granulosum.

Bacteriophages that lyse C. acnes were described by Brzin (1964) and have been used to show a similarity between certain named strains (Zierdt et al., 1968). C. avidum is not susceptible to the action of bacteriophage (Reid and Joya, 1969), and Voss (1970) found susceptibility in only one of his 26 group-II strains. In a previous study, we isolated eight phages from cultures of the skin of the normal forehead and found that anaerobic diphtheroids were either susceptible or resistant to lysis by all the phages (Marples, 1974). We selected two of these phages (A and G), which differed in the morphology of their plaques,

Received 28 Sept. 1973; accepted 24 Dec. 1973.

Present address: Cross-Infection Reference Laboratory, Central Public Health Laboratory, Colindale Avenue, London, NW9 5HT.

J. MED. MICROBIOL.-VOL. 7 (1974) 
and used them in a study of anaerobic diphtheroids from acne comedones (Marples, McGinley and Mills, 1973). Group-II strains were found to be more frequent and numerous in severe than in mild acne lesions. In a later investigation (Marples et al., 1974) we confirmed that this was also true of anaerobic diphtheroids from the skin of acne patients.

Because tests for DNA homology and cell-wall analysis are not practicable in a clinical laboratory, we investigated the possibility of subdividing the anaerobic diphtheroids by colonial morphology and phage susceptibility and examined 200 strains for biochemical and enzymic activity. The cultures examined had been isolated during several quantitative microbiological studies of the normal flora of healthy volunteers and of acne patients.

TABLE I

Origin of the strains of anaerobic diphtheroids examined biochemically

\begin{tabular}{|c|c|c|c|}
\hline \multirow{2}{*}{ Site } & \multicolumn{3}{|c|}{ Number of strains isolated from the stated site in } \\
\hline & normal patients & acne patients & all patients \\
\hline $\begin{array}{l}\text { Scalp } \\
\text { Forehead } \\
\text { Cheek } \\
\text { Alae nasi } \\
\text { Axilla } \\
\text { Back } \\
\text { Open comedo } \\
\text { Closed comedo } \\
\text { Unknown } \ddagger\end{array}$ & $\begin{array}{c}23 \\
25^{*} \\
0 \\
9 \\
23 \\
6 \\
0 \\
0 \\
\ldots\end{array}$ & $\begin{array}{c}4 \\
20 \\
6 \\
3 \\
0 \\
0 \\
39+ \\
38 \\
\ldots\end{array}$ & $\begin{array}{r}27 \\
45 \\
6 \\
12 \\
23 \\
6 \\
39 \\
38 \\
4\end{array}$ \\
\hline
\end{tabular}

\section{MATERIALS AND METHODS}

Strains examined. More than 1100 strains from human skin or from acne lesions were used in studies of colonial morphology and phage susceptibility. Of these, 510 consecutive isolates were first classified into group I or group II according to the appearances of their colonies, and then the results of the phage tests were read. Biochemical tests were performed on 194 selected strains-85 from normal skin and 109 from acne patients (table I) and on the following reference strains: no. ATCC6919 (P. acnes); no. ATCC11829 (C. parvum); no. 545 , a poor lipase producer and no. 466 , a good lipase producer from human skin (Ray and Kellum, 1970); nos. 3 and 15 (our stock strains of $C$. acnes group I and group II from the skin of a normal forehead and an open comedo respectively). Apart from these reference strains, each strain examined was derived from a quantitative sample taken into detergent fluid either by the scrub method (Williamson and Kligman, 1965) or by homogenisation in detergent of material from an acne comedo. The primary plates were incubated at $35^{\circ} \mathrm{C}$ for 7 days in an atmosphere of $90 \% \mathrm{~N}_{2}+10 \% \mathrm{CO}_{2}$ in anaerobic jars containing copper-coated steel wool to remove traces of oxygen.

Some selection of strains from acne patients was made in the later parts of the study. To increase the number of phage-resistant strains subjected to biochemical testing, typical group-I strains were not selected for further examination nor from more than one skin site, usually the forehead, of the three sites sampled in each patient.

Colonial morphology and phage susceptibility. The appearance of isolated colonies on the primary plates was recorded. One colony of each type was streaked on a half-plate of modified Marshall and Kelsey casein-yeast-lactate-glucose agar (CYLG) (Marples, McGinley 
and Mills, 1973). A drop of the test dilution of each of the two bacteriophage suspensions (phages $A$ and $G$ ) was placed on the heavily inoculated area and the plate was incubated anaerobically at $35^{\circ} \mathrm{C}$ for 7 days before being examined for phage lysis.

Suspensions of the two bacteriophages were prepared as follows. Drops $(0.05 \mathrm{ml})$ of a stock suspension of phage, diluted to give semiconfluent lysis on the propagating strain, were placed on the surface of a plate of CYLG agar that had been freshly inoculated with a heavy broth suspension of $C$. acnes strain no. 3. After incubation at $35^{\circ} \mathrm{C}$ for 4 days the growth was harvested in MR-VP Broth \{Baltimore Biological Laboratories (BBL)\} and passed through a $0.45-\mu \mathrm{m}$ Swinnex Millipore filter. The strength of the phage was measured by plating drops of ten-fold dilutions of filtrate on a heavy lawn of $C$. acnes strain no. 3 and incubating for 4 days. The dilution giving semiconfluent lysis was prepared freshly for susceptibility testing.

Cultural and biochemical tests. Each strain was again subcultured at least once and always 7 days before biochemical testing. A heavy suspension in $1 \%(w / v)$ peptone water was prepared from growth on the streak plate. Trypticase-Nitrate Broth (BBL) was seeded with four drops of this suspension. Solid media were seeded by lightly pressing on the surface a cotton-tipped swab moistened with the broth suspension. This produced an even circular area of growth approximately $1 \mathrm{~cm}$ in diameter. Divided plates gave better results, but four strains could be tested on an undivided $100-\mathrm{mm}$ plate. All tests were incubated at $35^{\circ} \mathrm{C}$ for 7 days, the solid media in $\mathrm{N}_{2}+\mathrm{CO}_{2}$ as before. A plate of CYLG agar was also streaked to test the purity of the suspension.

With the exceptions noted below, the basal medium for the tests was CYLG. The growth on the purity plate was examined for colonial morphology and was used for microscopic examination and for tests of catalase-by the addition of a drop of $3 \% \mathrm{H}_{2} \mathrm{O}_{2}-$ and oxidase production, with tetramethyl-p-phenylenediamine (Cowan and Steel, 1965). Haemolysis was sought on Trypticase Soy Agar (BBL) supplemented with $0.5 \%(\mathrm{w} / \mathrm{v})$ of yeast extract and containing $5 \%(\mathrm{v} / \mathrm{v})$ of sheep blood; it was recorded as "complete" ( $\beta$-haemolysis) or " incomplete" (greening only). DNAase was detected as clearing when incubated plates of the basal medium with the addition of $0.2 \%$ DNA was flooded with $1 \mathrm{~N} \mathrm{HCl}$ to precipitate unhydrolysed DNA. Gelatin similarly was tested at $0.4 \%$ and precipitated with acid mercuric chloride. Casein hydrolysis was sought on standard-methods casein agar (SMCA) (Martley, Jayashankar and Lawrence, 1970) and recorded as " precipitate " or "clearing". Indole and nitrate reductase were tested in the liquid Trypticase Nitrate Broth (BBL) by standard methods (Cowan and Steel, 1965). Glucose, maltose, mannitol, sucrose, sorbitol, trehalose, and lactose were incorporated at $1 \%$ in thioglycollate agar (BBL) supplemented with $0.5 \%$ yeast extract and with brom-cresol purple as indicator. Aesculin hydrolysis was detected by fluorescence (Cowan and Steel, 1965). For esterases, tests with polyethoxy-sorbitan esters (Tweens $20,40,60$, and 80 ) at $1 \%$ in CYLG agar were satisfactory because the medium contains enough calcium to precipitate soaps; hydrolysis was recorded as weak or strong. Tributyrin, trilaurin, triolein, and tripalmitin were homogenised int oCYLG agar before pouring to give a weakly milky medium. Lipase activity was detected by clearing and was recorded as weak or strong. Tolerance of high salt concentrations was tested by growth on plates containing $5 \%$ and $10 \% \mathrm{NaCl}$ compared with growth on a control plate.

\section{RESULTS}

\section{Bacteriophage susceptibility}

Strains were readily assigned to a phage-susceptible group I, in which there was confluent lysis in the drop area, and a phage-resistant group II in which there was no naked-eye evidence of phage action.

\section{Colonial morphology}

After incubation for 7 days on CYLG agar, phage-susceptible group-I strains formed circular, 1- to 2-mm diameter, dome-shaped, cream or yellow 
colonies. The colonies were smooth but not shiny, and were opaque, butyrous, and emulsified easily in water (the figure, A). Group-II strains formed more variable colonies, though larger than group I; group-IIA strains formed the largest colonies. Most group-II colonies were circular, 3-4 mm, dome-shaped, entire, distinctly reddish-brown in colour, and with a smooth dull or shiny surface (the figure, B and C). The consistency was pasty and emulsification in water was difficult. Some strains formed circular, 4-mm, lobate, conical colonies with a matt surface, pale cream in colour, opaque, friable, and emulsifying only to a granular suspension (the figure, D).

On other rich media such as brain-heart-infusion dextrose agar the colonial characteristics could be seen but not as clearly as on CYLG agar. Poorer media or shorter incubation did not permit the two groups to be separated by colonial morphology.

To test the ability of an experienced bench-worker to predict susceptibility to bacteriophage from the colonial appearance, 510 isolates from 113 samples were classified as group I or group II on colonial morphology alone. This classification agreed with the result of the bacteriophage-sensitivity tests in $89.3 \%$ of the phage-susceptible and $95.4 \%$ of the phage-resistant strains, a total rate of agreement of $93.8 \%$. The lower figure for phage-susceptible strains was partly due to a search having been made for phage-resistant strains in scalp samples, where $23 \%$ of 30 sensitive isolates were wrongly classified as group II by colonial appearances. More than $95 \%$ of correct predictions of sensitivity were made with 198 isolates from the forehead and the alae nasi, and from acne lesions.

The results of the biochemical tests on the 200 strains examined are summarised in table II. They show that the two groups defined by susceptibility to the bacteriophages can also be differentiated biochemically. All strains were Gram-positive bacilli of coryneform morphology. Nearly all of the phagesensitive strains were indole positive, DNAase negative and reduced nitrate, and most produced acid from sorbitol but not from sucrose or trehalose, whilst phage-resistant strains usually had the reverse characteristics.

The phage-resistant strains (group II) could be subdivided into a proteolytic subgroup (IIA) and a non-proteolytic subgroup (IIB). Of 112 strains, 29 attacked gelatin and casein and 71 attacked neither. The remaining 12 strains were allocated to the most appropriate group by means of their other characters. Among the group-IIA strains, $79 \%$ produced $\beta$-haemolysis on sheep-blood agar. Acid production from the "sugars" was more frequent in group-IIA than in group-IIB strains, as were strong reactions on the Tweens and some of the lipids. Group-IIA strains, tended to have a weaker action on DNA, and to be less often tolerant of $10 \%$ salt. Morphologically the cells of group-IIA strains were more frequently slender than were those of group-IIB strains. Further subdivision of group IIB by means of the tests used was not possible. Strains that did not produce acid from trehalose tended also to give negative results with sucrose and maltose but could not otherwise be grouped together.

The reactions of the two named strains are also listed in table II. The neotype strain of $P$. acnes (no. ATCC6919) was classified as a member of group I 
without difficulty. This strain was as susceptible to the bacteriophages as was the propagating strain (no. 3), and propagation on it gave a slightly higher yield of phage. The only anomalous result was a weak reduction of nitrate. Strain

TABLE II

Results of tests on 200 strains of anaerobic diphtheroids*

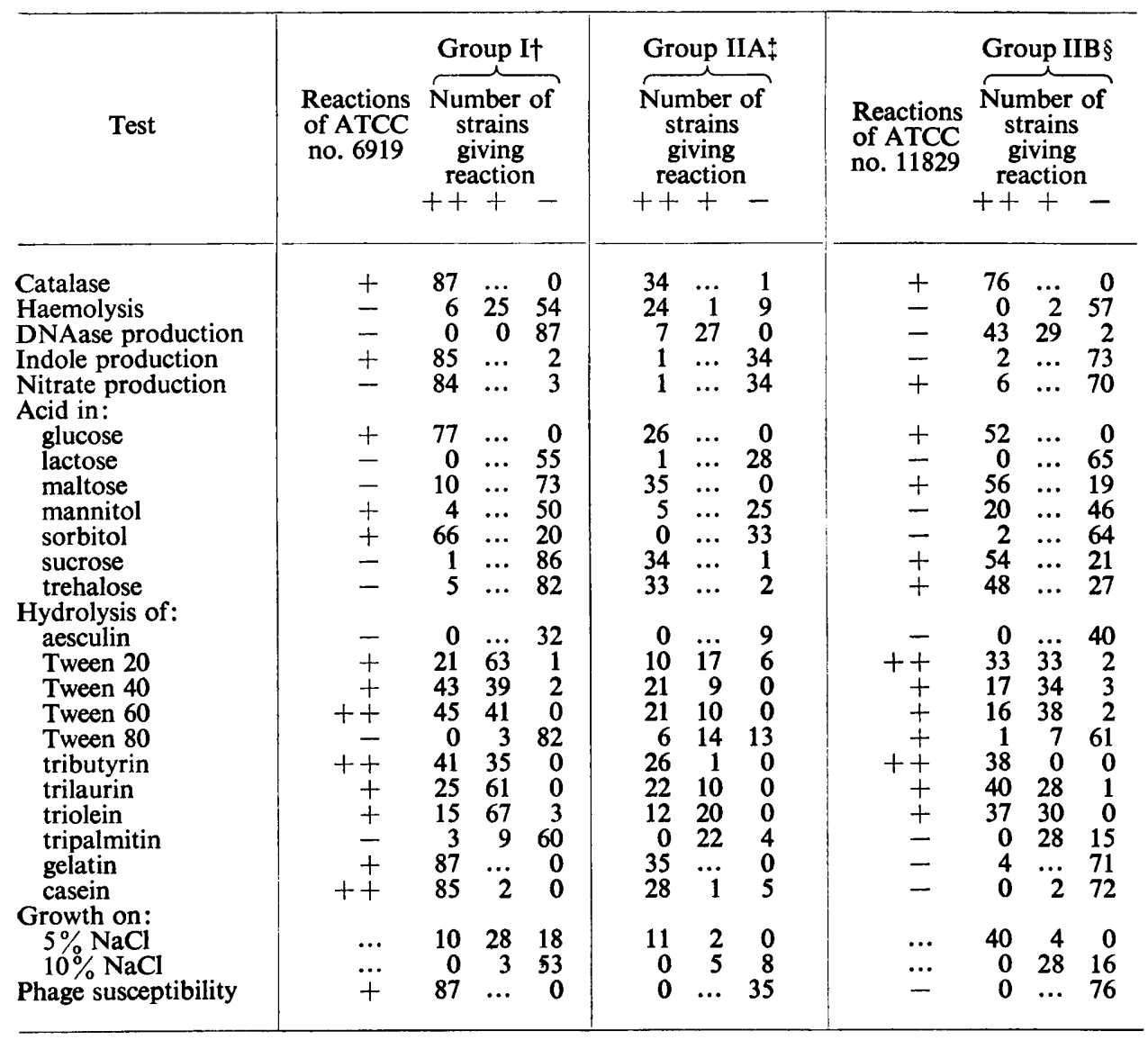

$++=$ positive reaction; $+=$ weakly positive reaction; $-=$ negative reaction (for definitions see text).

* All phage-susceptible strains were placed in group I and all phage-resistant strains in group II.

+ Includes strains nos. 3 and 466.

$\ddagger$ Includes strain no. 15 .

$\S$ Includes strain no. 545 .

no. ATCC11829, labelled $C$. parvum, fitted best into group IIB but gave only a very weak DNAase reaction, reduced nitrate and did not hydrolyse tripalmitin. The other reference strains were not remarkable, except that strain no. 15 (group IIA) was particularly active biochemically and was very strongly lipolytic. Ray and Kellum's strain no. 466 was classified as group I and strain no. 545 as group IIB. 


\section{Populations of anaerobic diphtheroids on normal human skin}

After the strains had been identified-the group-I strains by phage susceptibility and colonial morphology and the group-II strains also by means of the biochemical tests - the distribution of the groups and subgroups in the original samples was re-examined. Initially each colonial type had been enumerated and one colony of each type subcultured for testing from at least one site in each individual. The assumption was made that colonies of identical appearance from different sites on the same individual were identical. Group-II strains

TABLE III

Frequency of isolation and mean count of organisms from various skin sites in normal males

\begin{tabular}{|c|c|c|c|c|c|c|}
\hline \multirow{3}{*}{ Site } & \multirow{3}{*}{$\begin{array}{l}\text { Number } \\
\text { of } \\
\text { samples } \\
\text { examined }\end{array}$} & \multicolumn{5}{|c|}{$\begin{array}{l}\text { Number of samples* giving positive cultures } \\
\text { (and geometric mean count per } \mathrm{cm}^{2} \text { of positive samples) for }\end{array}$} \\
\hline & & \multirow{2}{*}{$\begin{array}{c}\text { any aerobic } \\
\text { organism }\end{array}$} & \multirow{2}{*}{$\begin{array}{l}\text { any anaerobic } \\
\text { organism }\end{array}$} & \multicolumn{3}{|c|}{ anaerobic diphtheroids, group } \\
\hline & & & & $\mathbf{I}$ & IIA & $\overrightarrow{\text { IIB }}$ \\
\hline $\begin{array}{l}\text { Scalp } \\
\text { Forehead } \\
\text { Back } \\
\text { Axilla } \\
\text { Alae nasi }\end{array}$ & $\begin{array}{l}72 \\
39 \\
46 \\
46 \\
15\end{array}$ & $\begin{array}{l}72\left(1.1 \times 10^{6}\right) \\
39\left(6.5 \times 10^{3}\right) \\
43\left(4.3 \times 10^{2}\right) \\
46\left(1.2 \times 10^{6}\right) \\
15\left(6.1 \times 10^{4}\right)\end{array}$ & $\begin{array}{l}72\left(6.4 \times 10^{5}\right) \\
36(1.2 \times 106) \\
35\left(1.4 \times 10^{5}\right) \\
39\left(4.2 \times 10^{4}\right) \\
15\left(1.7 \times 10^{7}\right)\end{array}$ & $\begin{array}{l}72\left(6.2 \times 10^{5}\right) \\
36\left(1.2 \times 10^{6}\right) \\
35\left(1.3 \times 10^{5}\right) \\
14\left(2.3 \times 10^{4}\right) \\
15\left(1.7 \times 10^{7}\right)\end{array}$ & $\begin{array}{r}0 \\
1\left(3.2 \times 10^{4}\right) \\
3\left(75 \times 10^{2}\right) \\
24\left(3.4 \times 10^{4}\right) \\
3\left(1.2 \times 10^{6}\right)\end{array}$ & $\begin{array}{r}16\left(8.9 \times 10^{4}\right) \\
6\left(2.1 \times 10^{2}\right) \\
13\left(2.2 \times 10^{4}\right) \\
12\left(3.2 \times 10^{4}\right) \\
11\left(1.4 \times 10^{5}\right)\end{array}$ \\
\hline
\end{tabular}

* Eluted from $3.8 \mathrm{~cm}^{2}$ of skin surface. For methods see Williamson and Kligman (1965) and Marples et al. (1971).

with the same biochemical reactions were considered " the same" even if their colonial appearances were somewhat different. The results of examining a total of 203 samples from four normal skin sites on 98 subjects taken by the localised detergent-scrub technique and 15 samples of weighed homogenates of material expressed from the follicles of the alae nasi in 15 other subjects could be reinterpreted after identification. The samples from the scalp, axilla, and back had been taken in duplicate while those from the forehead and alae nasi were unpaired. The samples from the axilla and back came from the same 23 subjects. The frequency of each group or sub-group and the geometric mean count per positive sample were then calculated from the reinterpreted analyses (table III). C. acnes group I was present in 172 of the 218 samples $(78.9 \%)$ and was by far the most numerous $\left(>10^{5}\right.$ per $\left.\mathrm{cm}^{2}\right)$ anaerobic diphtheroid at all sites except the axilla. Group-IIA strains were commonly found in the axilla in moderately large numbers, where 24 of 46 samples contained these organisms at a mean density of $3.4 \times 10^{4}$ per $\mathrm{cm}^{2}$, but were rarely found elsewhere ( 7 of 172 samples). Group-IIB strains were most frequent in follicular material, in the axilla, and on the back, but were rare on the forehead and scalp. When present, the population was of the order of $10^{4}$ per $\mathrm{cm}^{2}$ except on the forehead where lower densities were seen. 
ANAEROBIC DIPHTHEROIDS FROM SKIN
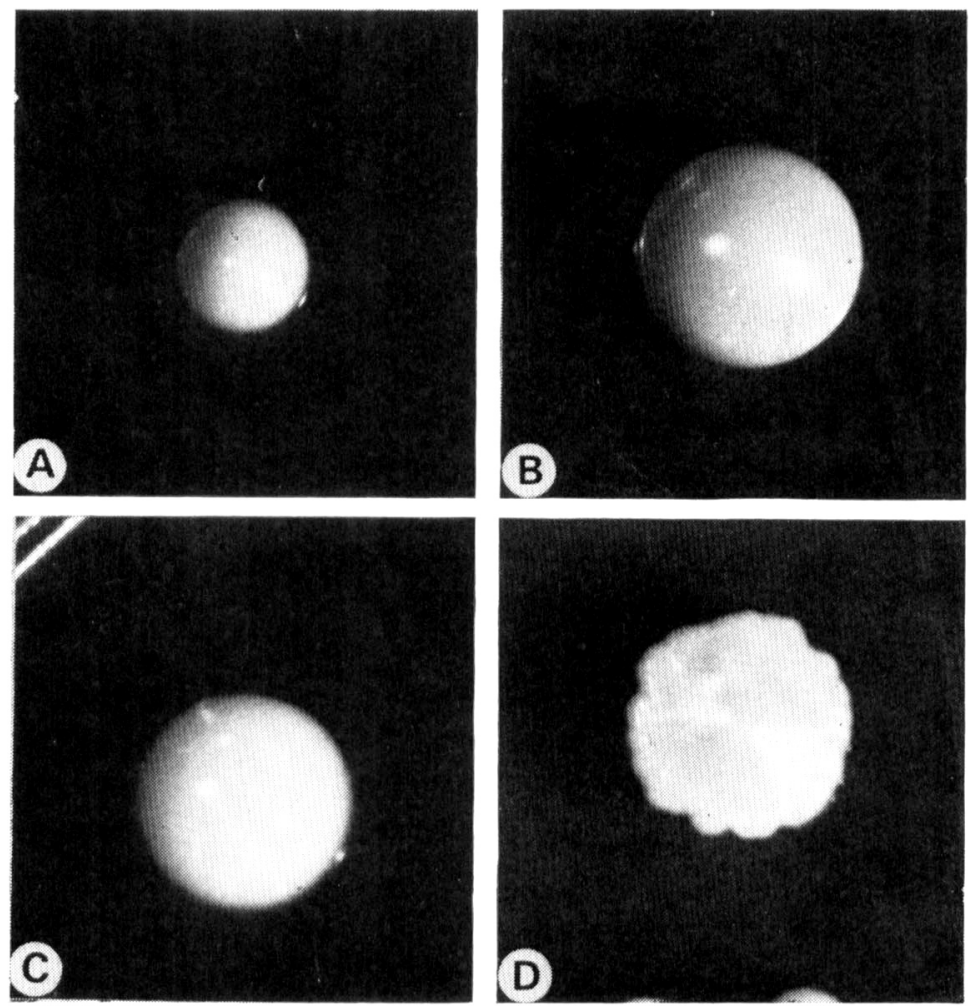

FIG.-Colonies of anaerobic diphtheroids growing on casein-yeast-lactate-glucose agar. A. Group I (Corynebacterium acnes). B, C, and D. Group-II strains. 


\section{Discussion}

The results of the biochemical study of 198 strains of anaerobic diphtheroids from human skin established that they could be divided into two groups and that the second of these could be subdivided. The main characters are shown in Table IV. The first group included the neotype strain of $P$. acnes (no. ATCC6919) and corresponds to C. acnes group I as described by Voss (1970). Although there is controversy over the correct generic nomenclature it suffices

TABLE IV

Biochemical classification of anaerobic diphtheroids from human skin

\begin{tabular}{|c|c|c|c|}
\hline \multirow{3}{*}{ Test } & \multicolumn{3}{|c|}{ Reaction of strains of } \\
\hline & \multirow{2}{*}{$\begin{array}{l}\text { group I } \\
\text { (C. acnes) }\end{array}$} & \multicolumn{2}{|c|}{ group II } \\
\hline & & $\mathrm{A}(C$, avidum $)$ & $\mathrm{B}(C$. granulosum) \\
\hline Phage susceptibility & + & - & - \\
\hline Haemolysis type & $\alpha$ & $\beta$ or - & - \\
\hline DNAase & - & + & + \\
\hline Gelatinase & + & + & - \\
\hline Casein hydrolysis & + & + & - \\
\hline Indole & + & - & - \\
\hline Nitrate reduction & + & - & - \\
\hline Sucrose & - & + & $d^{+}$ \\
\hline Sorbitol & $\mathrm{d}^{+}$ & - & - \\
\hline Trehalose & - & + & d \\
\hline Tween 80 & - & d & $d^{-}$ \\
\hline
\end{tabular}

$+=$ Reaction positive; $-=$ reaction negative; $d=$ reaction variable; $d^{+}=$reaction variable, usually positive; $d^{-}=$reaction variable, usually negative.

here to collect the strains into a single species, $P$. acnes or $C$. acnes, which could not be subdivided by the biochemical tests used. Johnson and Cummins (1972) thought that this species was divisible into two types according to the pattern of cell-wall sugars and the results of cell-wall agglutination tests, but found that there was $86-100 \%$ homology between the DNA of these types. We could identify strains of this group by susceptibility to the test bacteriophages and by their cream or yellow, medium-to-small colonies. The populations on normal skin were large. Diphtheroids of the group were almost invariably present on the scalp and forehead and formed the majority of the total flora on the forehead and back. They were almost always present in very large numbers in material expressed from follicles. We obtained further evidence of the high frequency and density of $C$. acnes group I in the lesions of acne (Marples, McGinley and Mills, 1973) and recently have extended these findings to the normal skin of acne patients (Marples et al., 1974).

Group-II strains differed clearly from those of group I (C. acnes) in several respects, notably in being resistant to bacteriophage, DNAase positive, and indole and nitrate negative as well as showing less consistent differences in carbohydrate fermentation. This group could be subdivided on the basis of proteolytic activity, haemolysin production, and differences in lipolytic activity. 
Group-IIA strains, which were proteolytic, lipolytic, and often haemolytic, were most frequently found in the axilla and were rare on the head or back. Because of the similarities to the reactions recorded for $P$. avidum (Holdeman and Moore, 1972) this name could be used for these strains. Non-proteolytic strains of group IIB could similarly be named $P$. granulosum. Johnson and Cummins (1972) found all the strains received from Voss as group II could be classified as $P$. granulosum. They found that $C$. parvum, no. ATCC11829, fell into the second of their types of $P$. acnes but we classified it, though with difficulty, as a member of our group IIB. Group-IIB strains were most frequent in follicular material from the nose and least frequent on the scalp and forehead. In our previous reports we did not subdivide group II and found the group as a whole to be more frequent and more numerous in patients with severe acne than in patients with milder disease. We found the highest incidence of group II in nasal swabs and in acne lesions and a lower incidence on the scalp, forehead and cheek (Marples et al., 1974).

It seems important to us to divide the anaerobic diphtheroids of the skin into groups because these then clearly differ in the sites in which they are found and in the biochemical effects of their growth. This has an immediate relevance to the problems of the pathogenesis of acne, but it is also of interest to discover whether isolates from deeper infections show the same frequency as is found on the skin of the arm or whether the proteolytic strains of group IIA and group I predominate.

\section{SUMMARY}

Eleven hundred and twenty-eight strains of anaerobic diphtheroids from human skin could be divided into two groups according to their colonial morphology on casein-yeast-lactate-glucose agar and their susceptibility to lysis by bacteriophages. Members of group I were sensitive and those of group II resistant to the action of phage. Biochemical tests confirmed this division among 200 strains, and permitted a subdivision of group II into a proteolytic and a non-proteolytic subgroup-IIA and IIB respectively. A simple scheme, based on colonial morphology, phage susceptibility, the production of indole, nitrate reduction, DNAase, gelatinase and caseinase formation, haemolysis, and the acidification of sucrose, sorbitol, and trehalose, could be used for the classification of these organisms.

Members of group I were most numerous on the skin of the scalp, forehead, and back, and in follicular material from the alae nasi. Group-IIA strains were found most often in the axilla, and group-IIB strains were occasionally present in small numbers at all sites.

\section{REFERENCES}

BRzIN, B. 1964. Studies on the Corynebacterium acnes. Acta. path. microbiol. scand., 60, 599.

Burtenshaw, J. M. L. 1945. Self disinfection of the skin. Br. med. Bull., 3, 161.

Cowan, S. T. AND Steel, K. J. 1965. Manual for the identification of medical bacteria. London.

Evans, C. A., Smrth, W. M., Johnston, E. A. AND Giblett, E. R. 1950. Bacterial flora of the normal human skin. J. invest. Derm., 15, 305. 
Holdeman, L. V. AND Moore, W. E. C. (editors). 1972. Anaerobe Laboratory Manual, VPI Anaerobe Laboratory, Blacksburg, Virginia, USA.

Johnson, J. L. AND Cummins, C. S. 1972. Cell-wall composition and deoxyribonucleic acid similarities among the anaerobic coryneforms, classical propionibactera and strains of Arachnia propionica. J. Bact., 109, 1047.

LACEY, R. W. 1968. Antibacterial action of human skin. Br. J. exp. Path., 49, 209.

LACEY, R. W. 1969. Loss of the antibacterial action of skin after topical neomycin. $B r . J$. Derm., 81, 435.

MARPLES, M. J. 1965. The ecology of the human skin. Springfield.

MARPLeS, R. R. 1974. The microflora of the face and acne lesions. J. invest. Derm., $62,325$.

Marples, R. R., Downing, D. T. and Kligman, A. M. 1971. Control of free fatty acids in human surface lipids by Corynebacterium acnes. J. invest. Derm., 56, 127.

Marples, R. R., Downing, D. T. and Kligman, A. M. 1972. Influence of Pityrosporum species in the generation of free fatty acids in human surface lipids. J. invest. Derm., 58, 155.

Marples, R. R., McGinley, K. J. AND Mills, O. H. JR. 1973. Microbiology of comedones in acne vulgaris. J. invest. Derm., 60, 80.

Marples, R. R., Leyden, J. J., Stewart, R. N., Mills, O. H. and Kuigman, A. M. 1974. The skin microflora in acne vulgaris. J. invest. Derm., $62,37$.

Martley, F. G., Jayashankar, S. R. AND Lawrence, R. C. 1970. An improved agar medium for the detection of proteolytic organisms in total bacterial counts. J. appl. Bact., 33, 363.

PRÉvot, A. R. 1966. Manual for the classification and determination of the anaerobic bacteria. (Translated by V. Fredette), Philadelphia.

PuHvel, S. M. 1968. Characterization of Corynebacterium acnes. J. gen. Microbiol., 50, 313.

Rasmussen, E. G., Gibbons, R. J. And Socransky, S. S. 1966. A taxonomic study of fifty gram positive anaerobic diphtheroids isolated from the oral cavity of man. Archs oral Biol., 11, 573.

Ray, L. F. AND Kellum, R. E. 1970. Corynebacterium acnes from human skin. Identification by morphological, cultural, biochemical, serological and chromatographic methods. Archs Derm., 101, 36.

REID, J. D. AND JoYA, M. A. 1969. A study of the morphologic and biochemical characteristics of certain anaerobic corynebacteria. Int. J. syst. Bact., 19, 273.

Rosebury, T. 1962. Micro-organisms indigenous to man. New York.

SMIth, R. F. AND Bodily, H. L. 1968. Identification of Corynebacterium acnes. Hlth Lab. Sci., 5, 100.

Strauss, J. S. And Kligman, A. M. 1960. The pathologic dynamics of acne vulgaris. Archs. Derm., 82, 779.

Südmersen, H. J. ANd Thompson, E. T. 1910. Cultivation and biological characters of Bacillus acnes. J. Path. Bact., 14, 224.

Voss, J. G. 1970. Differentiation of two groups of Corynebacterium acnes. J. Bact., 101, 392.

Williamson, P. And Kligman, A. M. 1965. A new method for the quantitative investigation of cutaneous bacteria. J. invest. Derm., 45, 498.

ZierdT, C. H., Webster, C. AND RUDE, W. S. 1968. Study of the anaerobic corynebacteria. Int. J. syst. Bact., 18, 33. 